\title{
How to maximize language learners' career readiness
}

\author{
Russell Simonsen \\ Miami University, Oxford, OH, USA \\ E-mail: simonsrl@miamioh.edu
}

Ensuring that students are 'career-ready' has become a common goal in language education over the past decade. The American Council on the Teaching of Foreign Languages (ACTFL) explains that language learning sequences must be carefully developed 'so that students are able to reach the Advanced level of Proficiency, 'career-ready' preparation' (ACTFL, 2020, para. 1). Because one of students' main educational motivations is to prepare for a career, it makes sense that ACTFL and language programs would want to promote the idea that advanced language abilities can increase employability. Although career-ready preparation is a worthy goal, it is often discussed in vague terms without a clear path toward achieving it. In light of recent data from employers regarding their linguistic needs, it is time to reassess the conceptualization of career readiness in language education in order to ensure that we provide students with skills and knowledge that will enhance their employability.

In this essay, I will review key findings from several different reports regarding the jobs that have a high demand for bilinguals and the skills that bilingual employees might be expected to possess. Two key findings are that: (1) employers in the finance/business and healthcare sectors have the highest demand for bilingual workers, and (2) language mediation (e.g., translation/interpreting) is a skill that is desired across the job market and one that employers often have to outsource due to a lack of in-house ability. These findings beg the question: As currently structured, are language programs adequately preparing students for the job market? I argue that the answer is often 'no', especially in the US, because of the marginalized status of language for specific purposes (LSP) classes (e.g., Spanish for Business) and the absence of national standards for language mediation. Language programs in the US can take concrete steps to remedy this situation, which include thoroughly integrating language mediation into curricula, as in the European model (Council of Europe, 2018), and increasing the prevalence of LSP classes.

\section{Defining career readiness}

The term 'career readiness' has grown in popularity in US education over the past decade, due in large part to the establishment of the Common Core State Standards (CCSS) - a shared set of kindergarten through 12th grade $(\mathrm{K}-12)$ educational standards that most States agreed to develop and adopt. The concept of career readiness was a fundamental consideration in the creation of the CCSS, as explained as follows: 'The CCSS are anchored by empirical evidence of what employers and educators actually demand of prospective employees and students. Indeed, standards were selected only when the best available evidence indicated that their mastery was needed for college and career readiness' (US Department of Education, 2013, p. 5).

Career readiness has subsequently been integrated as a goal at the university level. For example, the University of Minnesota lists the core competencies of career readiness that should be acquired as part of a liberal arts education: analytical and critical thinking, applied problem solving, ethical reasoning and decision making, innovation and creativity, oral and written communication, teamwork and leadership, engaging diversity, active citizenship and community engagement, and digital literacy (University of Minnesota, 2020). These core competencies are broad enough that they can be applied (C) The Author(s), 2021. Published by Cambridge University Press 
to virtually any subject within the liberal arts, including language learning. In fact, all of the skills listed above are supported either explicitly or implicitly in the most recent $\mathrm{K}$-university world language standards in the US, the World-Readiness Standards (WRS; The National Standards Collaborative Board [NSCB], 2015). While essential, these competencies are too general in that they do not fully exploit the special talents of language students. In the next section, career readiness will be discussed in terms of the specific skills that employers seek in multilingual employees, with a focus on language mediation (e.g., translation/interpreting). The subsequent section will explain how language mediation is largely absent from the WRS. This contrasts with the Common European Framework of Reference (CEFR; Council of Europe, 2018), which does place significant emphasis on the development of mediation.

\section{Job demand, employers' needs, and how they relate to career readiness}

Employers who are seeking to hire bilingual employees often desire specific skills in addition to the general competencies listed in the previous section. First, as expected, employers want bilingual employees to be highly proficient in two languages. In the US, this is usually English and an additional language. Beyond advanced language proficiency, the specific language skills and knowledge required by employees vary depending on the job. Therefore, the first question we must ask is, 'Who are the employers and what are the jobs?'

Based on a report from New American Economy (2017) that tracked millions of job postings between 2010-2015, the three employers that had the highest demand for bilinguals specialized in banking, tax preparation, and healthcare: Bank of America, H\&R Block, and Humana. The majority of job listings posted by Bank of America were for sales agents and financial managers. H\&R Block most frequently sought tax preparers and receptionists/information clerks. Humana most frequently sought registered nurses and medical assistants. To offer a more concrete picture of the demand for bilinguals, more than one-third of the Bank of America's job postings in 2015 targeted bilinguals. In the case of Humana, one-fourth of online posts were for bilinguals, including $40 \%$ of advertisements for registered nurses.

The majority of the jobs with high demand for bilingualism mentioned above have the following in common: they require skills and knowledge that are most directly targeted in academic programs related to business and healthcare. For instance, being a financial manager usually requires a bachelor's degree in business administration, finance, economics, or accounting. A nurse requires a nursing degree, and medical assistants are usually expected to obtain national credentialing (e.g., Certified Medical Assistant). Of note is that the job outlook is particularly rosy for several of these careers. Financial manager and medical assistant are categorized as jobs with 'much faster than average' projected growth rates $-15 \%$ and 19\% between 2019-2029, respectively (US Bureau of Labor Statistics, 2020). Despite this growing need in the job market, the development of language skills and content knowledge that are specific to business and healthcare often occurs only peripherally in language programs, in LSP courses that students take as optional electives (Doyle, 2017), which will be discussed later.

\section{Specific language skills needed by employers}

The specific language skills required for many careers can be quite different from the ones targeted in language classes in which general proficiency is the primary goal. The Language Flagship, which is part of the US Department of Defense, set out to understand the language skills that were needed in a diverse cross-section of the labor force, including hotel and travel, food services, aviation, waste and water management, law firms, banking, engineering and industrial development, automobile industry, and high technology. The Language Flagship found that the majority of businesses that have international dealings 'need language skills for translation, interpretation, and localization of products and services' (Duggan, 2009, p. 7). And, when businesses were lacking these crucial skills, it was considered a significant barrier to international expansion.

Because two-thirds of companies lack the necessary in-house language skills to be able to independently manage their crosslinguistic communications, they rely on third-party language services 
(e.g., a translation/interpreting company; ACTFL, 2019). However, many employers are not keen on utilizing such services for several reasons. One reason is that outside language experts do not always have extensive knowledge of the technology and processes, products, or relationships between businesses and clients (Duggan, 2009). These shortcomings can lead to misunderstandings, and negatively affect profits. For example, it is estimated that two billion dollars are lost each year in the US economy due to miscommunication and cultural misunderstandings (New American Economy, 2017). Another reason that some businesses dislike using third-party language services is the high cost. One business leader summarized an experience with a translation company in the following way: 'nothing worked terribly well, and it was all very expensive' (Duggan, 2009, p. 7).

For the foreseeable future, because employers cannot meet their language needs with in-house talent, the fields of translation and interpreting are expected to thrive. In fact, researchers at the University of California San Diego identified 'interpreters and translators' as the number one emerging career for US college graduates in 2017, and they predicted that this profession would grow by $31 \%$ between 2016 and 2026 (Shapiro et al., 2017). While translation and interpreting services are in high demand and are fundamental to global communication, I argue that language programs in the US, on the whole, do not adequately prepare enough students for careers that require these skills.

\section{Career readiness within world language education}

The curricular offerings of language programs are not always balanced in a way that prioritizes the skills and knowledge needed for some of the most common careers. For instance, LSP courses such as Spanish for Business or Spanish for Healthcare are often provided as stand-alone electives that do not have an articulated sequence even though business and healthcare are two of the sectors with the highest demand for bilinguals (New American Economy, 2017). Doyle (2017) explains that LSP courses are still 'coming of age' and do not yet have the 'curricular importance and exceptionalism claimed traditionally by other emphases, such as literary studies' (p. 96). Businesses also appear to have noticed the dominance of literary studies in language departments and have expressed a desire for change. For example, when the Language Flagship asked US companies how universities could better prepare students with language and cultural skills for the workforce, one of their suggestions was 'Have students certified for their language skills at the university level without having to be literature majors' (Duggan, 2009, p. 10). Although employers are not experts in curriculum design, their perspective is certainly relevant when discussing career readiness given that students' education is a vital part of career preparation. What is more, many businesses are seeking to develop stronger ties with educational institutions. In a recent survey, $86 \%$ of employers wanted improved outreach from universities (Daniel et al., 2014), so there are assuredly many connections to be made between businesses and language programs in the future.

In addition to expanding LSP course offerings, it is also important to target the development of language skills that many employers need but are often underdeveloped in language programs. The most common language skill that employers lack and therefore have to outsource, is translation (ACTFL, 2019). Even if students plan to use their languages locally and for community engagement, the ability to mediate between languages will likely still be important. Colina and Lafford (2017) report that translation and interpreting are two of the most common tasks that second language (L2) Spanish learners complete when they are placed with local businesses and organizations through internships or service-learning projects in the US. Therefore, written and spoken language mediation should be considered a versatile skill useful in a wide array of careers - not just careers in competitive, for-profit industries.

\section{Messaging from language organizations}

Language organizations in the US have attempted to highlight the benefits of language learning in terms of career preparation. However, career readiness is sometimes discussed in a vague way, which does not lead to a clear understanding of how learning a language prepares students for a career. 
Here is one example from the WRS: 'Learners who add another language and culture to their preparation are not only college- and career-ready, but are also 'world-ready' - that is, they bring additional knowledge, skills, and dispositions to add to their resume for entering postsecondary study or a career' (NSCB, 2015, p. 16). This quote suggests that all learners of additional languages and cultures are career-ready, but this can be misleading, as will be discussed in the next paragraph. Another vague reference to career readiness can be found in ACTFL's (2020) discussion of articulated sequences in language learning. ACTFL states that language learning sequences 'must be well-articulated from elementary schools through post-secondary programs, so that students are able to reach the Advanced level of Proficiency, "career-ready" preparation' (para. 1). Based on this statement, educators might get the impression that advanced proficiency is a sufficient threshold for career readiness. However, this is not always the case.

Learning a second language and attaining advanced proficiency should be considered necessary but not always sufficient - for career readiness. For example, in order to effectively translate or interpret, which are two commonly needed language skills in the workforce (ACTFL, 2019; Colina \& Lafford, 2017), language learners need specialized training. The American Translators Association (2011) explains why advanced speakers are not necessarily equipped with these abilities: 'bilinguals may speak two languages fluently, but ... they are not necessarily good at moving information between the two languages, especially when the pressure is on' (p. 7). An international public health crisis such as the COVID-19 pandemic is an example of a high-pressure context in which 'clear and precise communication' is vital for 'the health and security of every nation' (British Academy et al., 2020, p. 1). Bilingual language experts working in such a context should not only have advanced proficiency, but also training in translation/interpreting in order to ensure seamless communication between governments, researchers, and healthcare workers.

Colomer (2010) documented an additional context in which advanced proficiency does not guarantee successful communication in the workplace. She found that many K-12 Spanish teachers struggle when they are called upon (usually inappropriately) to serve as interpreters in communities with emerging Latino populations in the US. Although all of the teachers in Colomer's study had an advanced-low proficiency or higher on the ACFTL scale, several mentioned that their college preparation and the classroom-specific language that they were accustomed to did not prepare them for interpreting encounters with students' Spanish-speaking parents. In other words, effective language mediation is not a skill that typically emerges naturally from having advanced proficiency in both a first language (L1) and L2. Due to the fact that bilinguals are often expected to mediate language as part of their job (Colina \& Lafford, 2017; Colomer, 2010), language organizations should emphasize that career-ready preparation often requires more than general advanced proficiency.

In the WRS, there is very little reference to language mediation, and it is not incorporated into any of the ' 5 Cs': Communication, Culture, Connections, Comparisons, and Communities. Although the Comparisons standard calls on students to make observations about the similarities and differences between their L1 and L2, this is not the same as learning to move between the two languages, as mentioned above (American Translators Association, 2011). The lack of focus on language mediation in the WRS may be a result of major shifts that took place in language education in the previous century. Colina and Lafford (2017) explain that the emphasis on translation largely fell out of favor in language classrooms in the twentieth century due to the rejection of the grammar translation method and the rise of communicative methods that encouraged teachers to use the L1 as little as possible. As Cook (2007) points out, advocating for little-to-no use of an L1 is an implicit rejection of translation and interpreting.

In addition to translation being largely excluded from the WRS, it is framed as a source of distortion in a discussion of 'authentic materials', which are described as multimedia and print materials 'prepared in the target language by and for native speakers' (NSCB, 2015, p. 86). The authors comment that ' $\mathrm{t}$ ] hese materials - whether creative works, documentaries, or online information - provide unique perspectives not DISTORTED BY TRANSLATION' (NSCB, 2015, p. 86; emphasis my own). This implies that translation has an undesirable, distorting effect on the perspectives expressed in materials. Nevertheless, the degree to which translation 'distorts' perspectives is a linguistic and philosophical question, and by and 
large there are few perspectives that cannot be expressed in a SIMILAR way across languages. In fact, if an aspiring translator were to express a perspective from a Spanish text in a significantly different way in an English translation, this would change the meaning in most cases, and would contribute to a failing score on a translation exam. To minimize any distortions, translators rely on their 'knowledge of the social, contextual and experiential grounds of meaning in the two languages and cultures that they broker' (Jaffe, 1999, p. 48). This is precisely the knowledge that students could develop in an articulated language learning sequence that included language mediation as an essential component of the curriculum.

In contrast to the WRS, the CEFR (Council of Europe, 2018) highlights the importance of language mediation by including it as one of the elements of plurilingual competence. Mediation is defined as the act of making 'communication possible between persons who are unable, for whatever reason, to communicate with each other directly' (Council of Europe, 2018, p. 33), and it encompasses both written and oral communication. This definition is broad enough to describe the passing of information across different languages and within the same language. Although crosslinguistic mediation is more common, mediation is sometimes necessary among speakers of the same language due to differences in dialect, register, or even culture. For example, a parent who simplifies a complex medical diagnosis from a doctor so that a child can understand it is performing mediation within a single language. Alternatively, an interpreter who conveys a diagnosis from an English-speaking doctor to a Spanish-speaking patient is performing crosslinguistic mediation. In the CEFR, mediation is given an unambiguously important status, which is reflected by its inclusion as one of the four modes of communication, alongside reception, production, and interaction. Additionally, a full range of descriptor scales for this ability was recently developed (A1 to C2 proficiencies). Given that language mediation is a versatile ability that is crucial in many different lines of work, the CEFR is leading the way in the campaign to equip students with practical skills for future careers.

\section{Moving forward}

One way for language programs to enhance students' career readiness would be to employ at least one LSP specialist who could develop a strong curriculum in this area. However, making changes to course offerings and personnel may be a challenging, long-term process. If LSP courses gain more prominence in language departments, as imagined by Doyle (2017), there may need to be a reduction of classes in the current dominant areas of literary and cultural studies. This could result in a power struggle since specialists in these dominant areas make up $79 \%$ of tenure-line faculty in Spanish departments, and 92\% in French departments, at least at large research institutions (VanPatten, 2015). Therefore, although the expansion of LSP courses is an exciting possibility, it may require sustained advocacy at the departmental and institutional level in order for it to become a reality.

If expanding LSP options is not immediately achievable, educators can still advocate for the inclusion of more language mediation in the curriculum, because this skill is indispensable in bilingual students' career preparation and can be incorporated into virtually any course. While the development of language mediation has traditionally been reserved for LSP courses, scholars have recently called for it to become the 'fifth skill', complementing reading, writing, speaking, and listening (Colina \& Lafford, 2017; Cook, 2007). What is more, there is evidence of 'widespread support on the ground for the use of [translation in language teaching] in some form' (Kelly \& Bruen, 2015, p. 150). Moving forward, language mediation ought to be incorporated explicitly into state and national standards in the US with an articulated sequence of development, following the example set by the CEFR. We cannot leave the instruction of this skill to LSP courses, such as Spanish for Translation or Spanish for Healthcare. This is because LSP programs are still underdeveloped at most universities (Doyle, 2017), and also because language mediation is too important for students to develop minimally and peripherally.

\section{An exemplary language program}

On a final note, it may be helpful to highlight a specific institution that offers language students the career-ready preparation that has been promoted in this paper. One example is the University of Texas 
at Arlington, which has a comprehensive Spanish language program with several different degree options, many of which are career focused. For students who want a more traditional major with a balanced mix of language, literature, and culture, the Bachelor of Arts (B.A.) in Spanish for Global Competence would be most appropriate. If, however, students plan to develop language mediation as a professional skill, a B.A. or minor in Spanish Translation and Interpreting would serve them well. In yet a different scenario, imagine that a student wants to study Spanish in conjunction with another career focus, such as business. This student might opt for a Business Administration degree with a dual concentration in International Business and Spanish, which is offered by the College of Business Administration in cooperation with the Spanish language program. For a student pursuing a career in healthcare or other human services, a minor in Spanish for Global Health is also available. Finally, students who are interested in using Spanish in the non-profit sector can participate in an internship with a focus on service. The Spanish language program at the University of Texas at Arlington stands out due to its unequivocal commitment to career readiness.

\section{Conclusion}

Because career readiness is a desired outcome at an increasing number of academic institutions, it is in language educators' best interest to be able to articulate how they can uniquely contribute to this outcome. With this is mind, the most persuasive argument in support of language learning might not center around the general competencies or 'soft skills' that students develop, such as critical thinking, collaboration, empathy, and creativity. The reason is that these skills are also developed in many other areas of study, such as anthropology, social work, and philosophy, to name a few. On the other hand, language mediation and career-specific linguistic and cultural knowledge tend to be learned primarily in language classes, and these unique contributions align well with the needs of employers, as laid out in this paper. To ensure that language learning continues to stand out in terms of its contribution to career readiness, language mediation should be integrated into language standards in the US, following the CEFR, and LSP course offerings should be expanded according to students' and employers' needs.

\section{References}

ACTFL. (2019). Making languages our business: Addressing foreign language demand among U.S. employers. Author. https:// www.leadwithlanguages.org/wp-content/uploads/MakingLanguagesOurBusiness_FullReport.pdf

ACTFL. (2020). Articulated sequences in language learning. https://www.actfl.org/resources/guiding-principles-languagelearning/articulated-sequences-language-learning

American Translators Association. (2011). Interpreting: Getting it right. Author. https://www.atanet.org/publications/getting it_right_int.pdf

British Academy et al. (2020). The importance of languages in global context: An international call to action. https://www. thebritishacademy.ac.uk/documents/2737/Importance-Languages-Global-Context-Joint-Statement-Academies.pdf

Colina, S., \& Lafford, B. A. (2017). Translation in Spanish language teaching: The integration of a 'fifth skill' in the second language curriculum. Journal of Spanish Language Teaching, 4(2), 110-123.

Colomer, S. E. (2010). Dual role interpreters: Spanish teachers in new latino communities. Hispania, 93(3), 490-503.

Cook, G. (2007). A thing of the future: Translation in language learning. International Journal of Applied Linguistics, 17(3), 396-401.

Council of Europe. (2018). Common European framework of reference for languages: Learning, teaching, assessment. Companion volume with new descriptors. Author. https://rm.coe.int/cefr-companion-volume-with-new-descriptors-2018/ 1680787989

Daniel, S. J., Xie, F., Kedia, B. L., \& Lodge, W. (2014, April). 2014 Business needs for employees with international expertise. Paper presented at the Internationalization of US Education in the 21st Century: The Future of International and Foreign Language Studies conference, Williamsburg, VA. https://www.wm.edu/offices/revescenter/globalengagement/internationalization/papers\%20and\%20presentations/danielkediafull.pdf

Doyle, M. S. (2017). Spanish for the professions and specific purposes: Curricular mainstay. Hispania, 100(5), 95-101.

Duggan, S. J. (2009). What business wants: Language needs in the 21st century. The Language Flagship, National Security Education Program. https://www.nsep.gov/sites/default/files/What\%20Business\%20Wants\%20Report.pdf 
Jaffe, A. (1999). Locating power: Corsican translators and their critics. In J. Blommaert (Ed.), Language ideological debates (pp. 39-66). De Gruyter Mouton.

Kelly, N., \& Bruen, J. (2015). Translation as a pedagogical tool in the foreign language classroom: A qualitative study of attitudes and behaviours. Language Teaching Research, 19(2), 150-168.

New American Economy. (2017). Not lost in translation. http://research.newamericaneconomy.org/wp-content/uploads/ 2017/03/NAE_Bilingual_V9.pdf

Shapiro, J.D., Selfridge-Bustos, G., \& Carton, G. (2017). Emerging careers for college graduates. UC San Diego Extension. https://extension.ucsd.edu/UCSDExtension/media/UCSDExtensionsMedia/community-and-research/center-for-researchand-evaluation/2017-Emerging-Careers-Report.pdf

The National Standards Collaborative Board. (2015). World-Readiness standards for learning languages (4th ed.).

University of Minnesota. (2020). Career readiness. https://cla.umn.edu/career-services-office/career-readiness

U.S. Bureau of Labor Statistics. (2020). Occupational outlook handbook. https://www.bls.gov/ooh/

U.S. Department of Education. (2013). College and career readiness standards for adult education. Author. https://lincs.ed.gov/ publications/pdf/CCRStandardsAdultEd.pdf

VanPatten, B. (2015). Where are the experts? Hispania, 98(1), 2-13.

Russell Simonsen (Ph.D., University of Minnesota) is an assistant professor of Spanish at Miami University. His research at the intersection of second language acquisition and psycholinguistics examines how second language learners process sentences in real time, with a particular focus on syntactic and semantic factors. Additionally, he is a certified healthcare interpreter (Spanish/English) and is currently interested in the topics of language for specific purposes and career readiness in the context of second language learning.

Cite this article: Simonsen, R. (2022). How to maximize language learners' career readiness. Language Teaching, 55(2), 156-162. https://doi.org/10.1017/S0261444821000227 